\section{$L A-13578-P R$}

\section{Progress Report}

\section{Approved for public release;} distribution is unlimited.

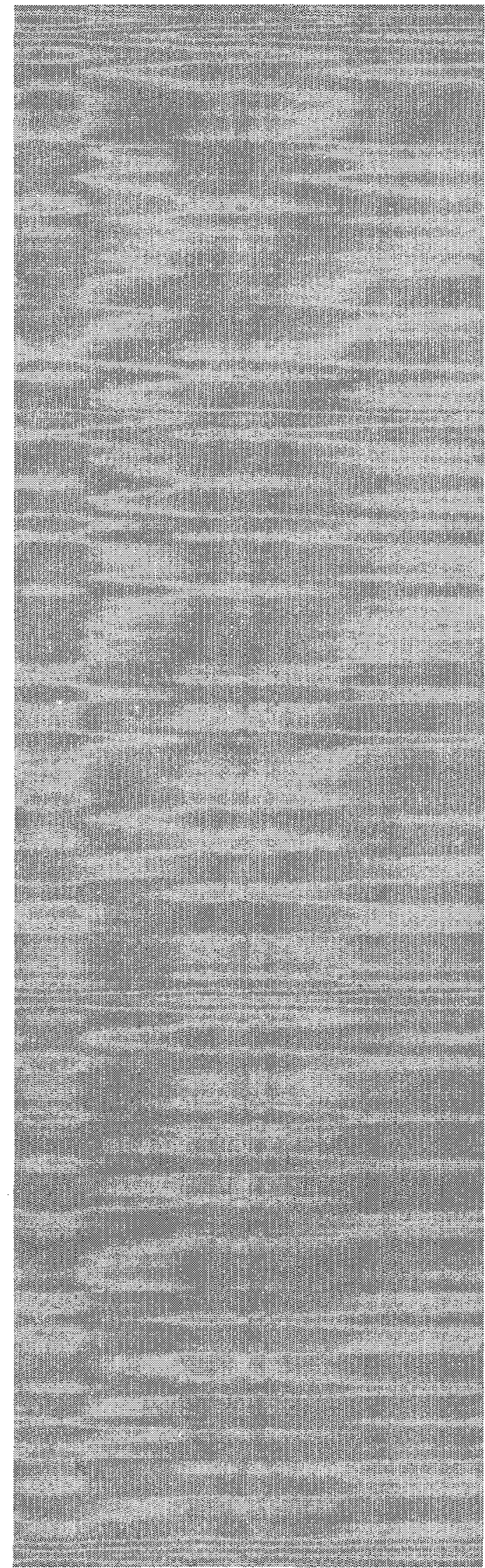

Monthly Progress Report

Heat Source Technology Programs

January to March 1997

\section{Los Alamos}

Los Alamos National Laboratory is operated by the University of California for the United States Department of Energy under contract W-7405-ENG-36. 
This work was supported by the US Department of Energy, Office of Nuclear Energy, Office of Special Applications.

The four most recent reports in this unclassified series are LA-13472-PR, LA-13491-PR, LA-13492-PR, and LA-13544-PR.

This report was prepared as an account of work sponsored by an agency of the United States Government. Neither The Regents of the University of California, the United States

Government nor any agency thereof, nor any of their employees, makes any warranty, express or implied, or assumes any legal liability or responsibility for the accuracy, completeness, or usefulness of any information, apparatus, product, or process disclosed, or represents that its use would not infringe privately owned rights. Reference herein to any specific commercial product, process, or service by trade name, trademark, manufacturer, or otherwise, does not necessarily constitute or imply its endorsement, recommendation, or favoring by The Regents of the University of California, the United States Government, or any agency thereof. The views and opinions of authors expressed herein do not necessarily state or reflect those of The Regents of the University of California, the United States Government, or any agency thereof. Los Alamos National Laboratory strongly supports academic freedom and a researcher's right to publish; as an institution, however, the Laboratory does not endorse the viewpoint of a publication or guarantee its technical correctness. 


\section{DISCLAIMER}

Portions of this document may be illegible in electronic image products. Images are produced from the best available original document. 
LA-13578-PR

Progress Report

Issued: May 1999

Monthly Progress Report

Heat Source Technology Programs

January to March 1997

T. G. George

Los Alamos

NATIONAL LABORATORY

Los Alamos, New Mexico 87545 



\section{CONTENTS}

ABSTRACT

I. HEAT SOURCE AND FEED POWDER SHIPMENTS

II. IRIDIUM HARDWARE SHIPMENTS AND INVENTORY $\ldots \ldots \ldots \ldots \ldots \ldots . . \ldots$

III. FACILITIES.
A. General
B. 7-in. Launcher Facility
C. Fuel Processing Laboratories
1. Glovebox Seismic Upgrades
2. Equipment Maintenance/Upgrade/Replacement
D. Aqueous Fuel Processing
E. Cold Support Facilities (TA-35)
1. Simulant Encapsulation Welding
2. Particle Size Analysis of Simulant Powders
F. CMR Building.

IV. GENERAL-PURPOSE HEAT SOURCE (GPHS) PROGRAM.

A. Heat Source Production/Capability Maintenance

1. Fuel Processing

2. Disposition of Process Residues

3. Calorimetry

4. Work Control Documents

B. Safety Test Program.

1. RTG/Thin-Fragment Test

2. Production Qualification Test Program

3. Bare Clad Impact Tests

C. Research and Development

1. High-Silicon Fuel Characterization (HSC) Study

2. Aqueous Recovery Operations...

3. Investigation of Urania/Plutonia Simulants.

4. Accelerated Oxygen Exchange

5. Helium Release Studies

E. Project Management

V. LIGHT-WEIGHT RADIOISOTOPE HEATER UNIT (LWRHU) PROGRAM. 14
A. Cassini Heat Source Production ....
B. LWRHU Production Qualification.
C. LWRHU Safety Testing: Sequential Impact Tests

VI. 60-WATT HEAT SOURCE

VII. 1-kW SHIPPING CONTAINER

VIII. PROGRAMMATIC MEETINGS AND VISITORS 


\title{
MONTHLY PROGRESS REPORT \\ HEAT SOURCE TECHNOLOGY PROGRAMS \\ JANUARY TO MARCH 1997
}

Compiled by

T. G. George

\begin{abstract}
This quarterly report describes activities performed in support of Cassini fueled-clad production and studies related to the use of ${ }^{238} \mathrm{PuO}_{2}$ in radioisotope power systems carried out for the Office of Special Applications of the U.S. Department of Energy (DOE) by Los Alamos National Laboratory (LANL). Most of the activities described are ongoing; the results and conclusions described may change as the work progresses.
\end{abstract}

\section{HEAT SOURCE AND FEED POWDER SHIPMENTS}

No heat source or feed powder shipments were received by or sent from Los Alamos National Laboratory (LANL) in the first three months of 1997.

\section{IRIDIUM HARDWARE SHIPMENTS AND INVENTORY}

No shipments of iridium hardware occurred in this quarter. The LANL inventory of General-Purpose Heat Source (GPHS) hardware, as of 31 March 1997, is shown in Table I.

\section{FACILITIES}

\section{A. General}

The laboratories used for fuel processing, fuel form fabrication, and encapsulation welding were generally available for routine operations in the first three months of 1997. However, operations in the laboratory used for processing ${ }^{238} \mathrm{PuO}_{2}$ powders were constrained by ongoing glovebox modifications required to meet more stringent facility seismic requirements. 
Table I. LANL Inventory of GPHS Iridium Hardware as of 31 March, 1997

\begin{tabular}{llc}
\hline $\begin{array}{l}\text { Type of } \\
\text { Hardware }\end{array}$ & Category & $\begin{array}{c}\text { Number of Items } \\
\text { in Inventory }\end{array}$ \\
\cline { 2 - 3 } PICS* & Prime & 74 \\
PICS & Restricted Use & 25 \\
Type II weld shields & Prime & 109 \\
\hline
\end{tabular}

\section{B. 7-in. Launcher Facility}

We continued to work to close out findings resulting from the Department of Energy (DOE) operational readiness review (ORR) of the 7 -in. launcher.

Because of the unexpectedly low impact velocity $(47.6 \mathrm{~m} / \mathrm{s})$ that occurred in bare-clad impact test number 34 (BCI-34) conducted on 25 November 1996 (the desired impact velocity was $55 \mathrm{~m} / \mathrm{s}$ ) and to address concerns associated with achieving the significantly higher velocities required for subsequent tests, we conducted a series of velocity verification tests in January and February, 1997.

On 29 January an unheated projectile was fired at a velocity of $76.1 \mathrm{~m} / \mathrm{s}$. In a second test conducted on 6 February, a heated projectile was fired at a velocity of $74.6 \mathrm{~m} / \mathrm{s}$; the desired impact velocity in both tests was $75 \mathrm{~m} / \mathrm{s}$. Procedure walkdowns and functional verification of support system (such as chilled water, etc.) operability were conducted before each test.

\section{Fuel Processing Laboratories}

\section{Glovebox Seismic Upgrades}

In February 1997, work began on upgrading many of the gloveboxes used for ${ }^{238} \mathrm{PuO}_{2}$ process operations to meet more stringent seismic requirements. The objective of this upgrade program was to ensure the seismic survivability of gloveboxes containing significant quantities of ${ }^{238} \mathrm{PuO}_{2}$ powder. The upgrade program was a required condition for DOE approval of the final safety analysis report (FSAR) for the plutonium facility.

On 4 February, upgrade work began on glovebox GB-251 in Room 201. This was the only glovebox in Room 201 that required a structural upgrade. Additional bracing and floorpads were installed the following week, and all seismic upgrade work on GB-251 was completed on 10 February. 
Upgrade activities were initiated in the primary ${ }^{238} \mathrm{PuO}_{2}$ fuel processing laboratories (Rooms 206 and 207) on 6 February. The seismic upgrades in these rooms were complicated by the fact that numerous glovebox services and large pieces of support equipment, such as atmosphere-conditioning dri-trains, were required to be disconnected and then removed before structural improvements could be installed. The number and extent of these removal operations effectively curtailed most ${ }^{238} \mathrm{PuO}_{2}$ processing operations during February and March. By the end of the quarter, upgrade work was nearly complete on four gloveboxes in Room 207: GB-224, GB-221, GB-266, and DB-7.

\section{Equipment Maintenance/Upgrade/Replacement}

\section{a. Gloveboxes}

Two gloveboxes located in Room 207 (GB-216 and GB-218) were previously identified as the first two gloveboxes that would be replaced under the DOE/NE-supported glovebox and equipment upgrade/replacement program. Both gloveboxes experienced significant degradation of window and spool gaskets as a result of their previous use as locations for ${ }^{238} \mathrm{PuO}_{2}$ fuel powder slugging and screening and were no longer in service. Throughout this quarter we provided additional information, as requested, to facility configuration control to facilitate removal of these gloveboxes. Although a work order for removal of the gloveboxes was prepared on 10 February, the priority of the seismic upgrade effort for crafts worker support precluded the initiation of any glovebox removal work during this quarter.

On $20 \mathrm{March}$, the two new gloveboxes that will be used to replace gloveboxes GB-216 and 218 were delivered to LANL.

\section{b. Hot Press \#3}

Work on the installation of a third hot press continued through mid-November, 1996. Design change packages (DCPs) for the next phase of installation work were prepared and submitted to facility configuration management. By the end of November, the DCPs had been reviewed by configuration management, and workers had been scheduled to bore a series of 4-in.-diameter holes through the concrete floor to accommodate radio-frequency (RF) cable hookups for the furnace portion of the new hot press. However, the priority of the seismic upgrade effort for crafts worker support precluded any progress on the installation of hot press \#3 during the first quarter of 1997.

\section{c. Waste Solidification Line}

In December 1996, workers assigned to the waste solidification line used to recover ${ }^{238} \mathrm{PuO}_{2}$ from contaminated aqueous solutions reported that the vacuum line required for solution filtration had ceased to function and that the caustic waste line used to dispose of filtered solutions had also been plugged. Preliminary investigation by facility management revealed that the vacuum line was completely occluded and that the plug in the caustic waste line could not be easily dislodged. Facility management subsequently recommended that 
the most expedient course of action would be to install a temporary connection bypassing the plug in the caustic waste line and to install a devoted wet-vacuum line for solution filtration. Unfortunately, the priority of the seismic upgrade effort precluded the availability of any crafts worker support for either activity during the first quarter of 1997. By 31 March 1997, a total of $60 \ell$ of contaminated solutions from ${ }^{238} \mathrm{PuO}_{2}$ process operations (capsule decontamination, metallography, chemical analysis) were awaiting treatment.

\section{d. Encapsulation Welding}

On 18 February, workers assigned to weld ${ }^{238} \mathrm{PuO}_{2}$ powder samples into containers for transport to the chemical analysis facility reported that the JETSTAR welding controller and Light-Weight Radioisotope Heater Unit (LWRHU) welding fixture (also used for welding of sample containers) were not operable. Subsequent troubleshooting of the controller indicated a problem with one of the electronic circuit boards. A replacement circuit board was ordered but did not arrive before the end of the quarter.

\section{e. Particle Size Analysis}

On 25 February, workers assigned to perform particle size analyses of ${ }^{238} \mathrm{PuO}_{2}$ and ${ }^{238} \mathrm{UO}_{2}$ powders reported that the BRINKMAN particle size analyzer was inoperable. Subsequent troubleshooting revealed a failure of the main circuit board inside the analyzer. Because replacement boards were no longer available from the manufacturer, the defective analyzer was scrapped and replaced by a duplicate unit previously used to perform particle size analyses of simulant powders at another facility.

\section{Aqueous Fuel Processing}

On 4 February 1997, final designs for two of the gloveboxes required to support the aqueous recovery of ${ }^{238} \mathrm{Pu}$ from process residues had been completed and were submitted to facility management for review.

\section{E. Cold Support Facilities (TA-35)}

\section{Simulant Encapsulation Welding}

As required by the "Simulant-Fueled GPHS Clad Welding Procedure" (SHS-NMT9PP-13), the JETLINE controller and HOBART power supply were recalibrated on 29 January, 1997.

\section{Particle Size Analysis of Simulant Powders}

On 4 March 1997, the BRINKMAN particle size analyzer used to characterize simulant fuel powders was removed from the cold support facility and installed in the LANL plutonium facility. Because a replacement unit was no longer available from the manufacturer, a search was initiated for comparable instruments that would obtain equivalent results. 


\section{F. CMR Building}

Throughout most of the quarter, one technician was assigned to sort, identify, and repackage ${ }^{238} \mathrm{PuO}_{2}$-contaminated waste materials that were discovered in the CMR building. These waste materials, which were stored in five 55-gal. drums, were generated as a result of activities conducted in the CMR building before 1989 in support of the Galileo and Ulysses space missions. Facility management assigned the removal and disposition of these materials as a responsibility of the Actinide Ceramics group.

\section{GENERAL-PURPOSE HEAT SOURCE (GPHS) PROGRAM}

\section{A. Heat Source Production/Capability Maintenance}

\section{Fuel Processing}

Although process operations were curtailed to facilitate the glovebox seismic upgrades, the accelerated deterioration of the fuel processing furnaces had a significant effect on our ability to perform oxygen exchange and granule seasoning. Of the nine furnaces dedicated to fuel processing, only four were operable for the entire quarter.

Fuel processing operations were performed on five fuel lots during the quarter. However, persistent difficulties in reducing the neutron emission rates of fuel lots below $8,000 \mathrm{n} / \mathrm{s} \cdot \mathrm{g}$ ${ }^{238} \mathrm{Pu}$, as well as the curtailment of process operations in March (to accommodate the seismic upgrade effort), prevented fabrication of any new GPHS or LWRHU fuel pellets.

\section{Disposition of Process Residues}

In the first quarter of 1997 , seven 8 -liter cans of ${ }^{238} \mathrm{PuO}_{2}$-contaminated cheesecloth generated during ${ }^{238} \mathrm{PuO}_{2}$-process operations were submitted for thermal decomposition (TDC) treatment to remove the combustible matrix. After TDC treatment, the cans were placed in temporary storage pending final disposition.

\section{Calorimetry}

On 4 February, we received a 500-watt calorimeter shipped from EG\&G Mound Applied Technologies in Miamisburg, Ohio.

\section{Work Control Documents}

On 19 February, a revision to Safe Operating Procedure (SOP) NMT9-SOP-0086, "Recovering Test Articles From IFIT Inner Catch Tube," was submitted for editing.

On 26 February, a draft of a new SOP for aqueous ${ }^{238} \mathrm{Pu}$ scrap recovery was completed and distributed for review. 
On 3 March, a revision to SOP HS-NMT9-PP-34, “ ${ }^{238} \mathrm{Pu}$ Waste Solidification," was submitted for editing.

On 10 March, a revision to SOP HS-NMT-9-PP-3, "Feed Introduction Process Procedure," was submitted for editing.

On 11 March, revisions to three SOPs (HS-NMT9-PP-23, "Dri-Train Operation;" SHSNMT9-PP-14, "Oxygen-16 Exchange Process Procedure;" and SHS-NMT9-PP-15, "Ball Milling Process Procedure") were distributed for use.

On 18 March, a revision to SOP HS-NMT9-PP-18, "Neutron Emission Rate Measurement," was distributed for use.

\section{B. Safety Test Program}

\section{RTG/Thin-Fragment Test}

The objective of the RTG/thin-fragment test was to provide information on the response of GPHS capsules, modules, and a loaded radioisotope thermoelectric generator (RTG) to conditions that might be experienced as a result of potential on- or near-pad accidents resulting from launch vehicle failure.

An RTG/thin-fragment test was conducted at the Sandia National Laboratories, Albuquerque (SNLA) rocket sled track on 26 March. In this test, a thin fragment was accelerated down the track where it impacted a simulated RTG section that contained GPHS modules loaded with simulant-fueled ( $\mathrm{UO}_{2},{ }^{235} \mathrm{U}$-depleted) GPHS capsules. The impact velocity was measured at $306 \mathrm{~m} / \mathrm{s}$, and the temperature of the module stack within the RTG was $1,090^{\circ} \mathrm{C}$.

The post-test examination and analyses of the impacted converter section and simulantfueled capsules were documented in previous monthly reports, and a final report on the test was published as report number LA-13220 in December 1996. A video summary of the RTG/thin-fragment test series was completed in January 1997 and forwarded to DOE/NE-50.

\section{Production Qualification Test Program}

The purpose of the production qualification test program was to determine whether heat sources fabricated at LANL had impact properties equivalent to those of heat sources fabricated at Savannah River and evaluated during the Galileo/Ulysses test program. Four GPHS capsules fabricated at LANL in 1994 were selected for use in the first production qualification test (PQ-1). 
In the PQ-1 test, a GPHS module loaded with capsules FC0018, FC0022, FC0031, and FC0038, was aged for 200 hours at a temperature of $1,287^{\circ} \mathrm{C}$ (clad surface). The module was then thermally treated to simulate a "min. gamma" atmospheric reentry. In an impact test conducted on 12 July 1996, the module was launched against a steel target at $54 \mathrm{~m} / \mathrm{s}$ and at $919^{\circ} \mathrm{C}$.

Postimpact evaluation did not reveal any evidence of a fuel release. The impacted module was relatively intact, and capsule deformations were relatively modest. The capsule strains and preliminary posttest observations have been documented in previous monthly reports.

When capsules FC0018 and FC0022 were defueled, noncontiguous areas of a thin white deposit were observed on the exterior surfaces of both fuel pellets. Similar deposits and some adjacent discoloration were observed on the clad interiors and on the weld-shields. Small sections for microprobe and scanning electron microscope (SEM) analyses were removed from both weld-shields and transported to the analytical facility at LANL's Chemistry and Materials Research (CMR) building.

In late 1996, efforts to perform microprobe and SEM analyses of the weld-shields were suspended because of the extremely high alpha contamination of the metal samples. In February 1997, metallographic cross sections of the weld-shields and iridium clads were forwarded to the CMR building. The reduced alpha contamination of these sections permitted microprobe analysis of the discolored areas. The results of these analyses revealed the presence of only $\mathrm{PuO}_{2}$.

\section{Bare Clad Impact Tests}

Two bare clad impact tests (BCIs) were performed at the end of November 1996, and two additional tests were performed in January (BCI-35) and February (BCI-36) of 1997. All four tests were part of the ongoing program to determine the similarity of GPHS capsules produced at LANL for the Cassini mission to capsules produced at the Westinghouse Savannah River Company (WSRC) in the early 1980s for the Galileo and Ulysses missions.

\section{a. BCI-33}

On 20 November 1996, GPHS capsule FC0334 was impacted against a steel plate at $55 \mathrm{~m} / \mathrm{s}$ and $1,093^{\circ} \mathrm{C}$. Before impact, the capsule was pretreated in a vacuum at $1,287^{\circ} \mathrm{C}$ (clad surface temperature) for $200 \mathrm{~h}$. Postimpact examination revealed that the exterior of capsule FC0334 was discolored and that the capsule was breached by two transverse cracks located on the cup radii at the edges of the impact face. No plutonia fines were observed on the interior of the tantalum impact can or in the catch tube. The capsule strains and other preliminary observations were reported in previous quarterly reports.

In this quarter we continued with the metallographic examination of sections removed from capsule FC0334. A sieve analysis of the fuel retained in capsule FC0334 was performed in March 1997; the results of this analysis are presented in Table II. 


\section{b. BCI-34}

On 25 November, GPHS capsule FC0336 was impacted against a steel plate at $47.6 \mathrm{~m} / \mathrm{s}$ and $1,090^{\circ} \mathrm{C}$. Before impact, the capsule was pretreated in a vacuum at $1,287^{\circ} \mathrm{C}$ (clad surface temperature) for $200 \mathrm{~h}$. Postimpact examination revealed that capsule FC0336 was breached by a transverse crack located on the vent cup radius at the edge of the impact face and by a weld failure that extended from approximately 30 to $185 \mathrm{deg}$ (with the weld start at $0 \mathrm{deg}$ ). However, the portion of the weld-shield under the weld failure did not breach and effectively prevented any significant release of plutonia. No plutonia fines were observed on the interior of the tantalum impact can or in the catch tube. The capsule strains and other preliminary observations were reported in previous quarterly reports.

In this quarter we continued with the metallographic examination of sections removed from capsule FC0336. An anomalous crack or delamination was observed in an axial section removed from the impact face of capsule FC0336. The "crack" was discontinuous, ran from the edge of the heat-affected zone (HAZ) into the shield cup, and had an approximate length of $6.3 \mathrm{~mm}$. Examination of sections from the capsule weld and weld failure did not reveal any unusual features. It did not appear that the weld failure occurred along the weld centerline.

A sieve analysis of the fuel retained in capsule FC0336 was performed in March 1997; the results of this analysis are presented in Table $\mathrm{II}$.

\section{c. BCI-35}

Capsule FC0339 was impacted against a $25.4-\mathrm{mm}$-thick structural steel plate at $55.7 \mathrm{~m} / \mathrm{s}$ and $1,090^{\circ} \mathrm{C}$ on 16 January, 1997. The capsule was pretreated for $200 \mathrm{~h}$ at $1,287^{\circ} \mathrm{C}$ (iridium alloy clad temperature) in vacuum before impact testing. The capsule impact face was centered at the weld start. Postimpact examination revealed that the clad was breached by two weld failures, one transverse crack, and one axial crack on the impact face of the capsule. A very small amount of plutonia was present in the tantalum impact can. No unusual discoloration of the capsule, impact can, or fixturing was observed.

The largest weld failure extended from one edge of the impact face (at approximately $330 \mathrm{deg}$ from the weld start to approximately $215 \mathrm{deg}$ ) and across the trailing face of the capsule. This crack measured approximately $1.8 \mathrm{~mm}$ at its maximum width, which was located at approximately $270 \mathrm{deg}$. The crack had an apparent length of approximately $30.4 \mathrm{~mm}$. At the terminus of the breach on the trailing face, the crack propagated axially into the vent cup for approximately $2 \mathrm{~mm}$. The weld shield was intact underneath the widest portion of the breach but was pierced by a displaced fuel fragment at the vent cup axial crack. Fuel was visible through the weld shield breach at this location. The other observed weld failure was a hairline crack that extended from approximately 105 to $160 \mathrm{deg}$ (length of approximately $16.9 \mathrm{~mm}$ ). This crack appeared to wander across and at times along the weld centerline. 
Table II. Particle Size Distribution of Fuel Recovered from BCI Tests

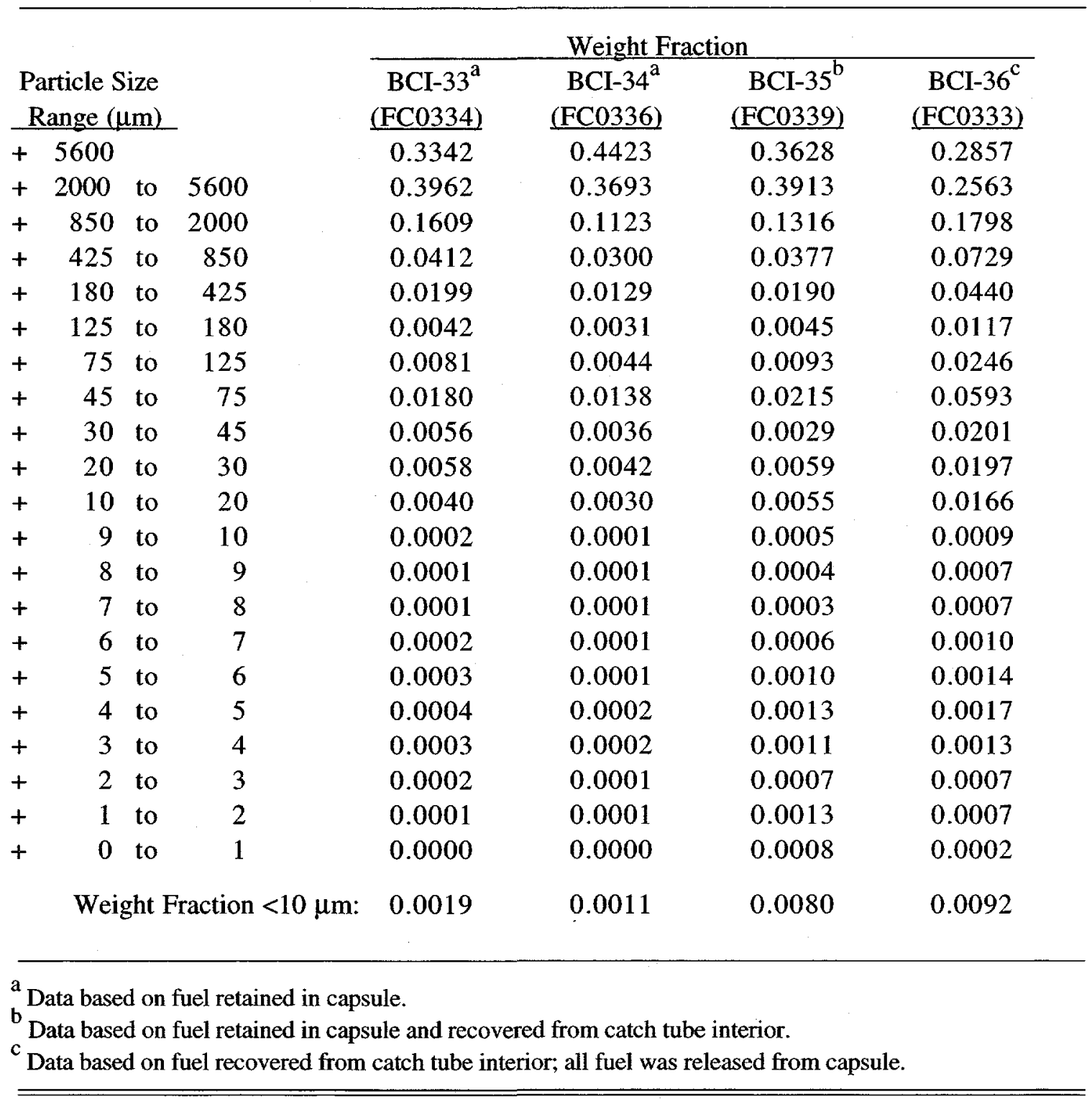

The transverse breaching crack in capsule FC0339 was located on the vent cup at the edge of the impact face. This crack measured approximately $13.7 \mathrm{~mm}$ in length and $0.94 \mathrm{~mm}$ at its maximum width.

After postimpact examination, the capsule was photographed, measured, and defueled. Deep creases that corresponded to some of the axial cracks were observed on the interior clad surface. No unusual discoloration or deposits were observed on the fuel pellet surface. A Quick-Look report that documented the preliminary findings of the postmortem examination was issued on 23 January. The capsule strains are compiled in Table III. 
Table III. BCI Capsule Strains

\begin{tabular}{|c|c|c|c|c|c|c|}
\hline \multirow{5}{*}{$\frac{\text { Test }}{\text { BCI-33 }}$} & \multirow[b]{4}{*}{ Capsule } & \multicolumn{5}{|c|}{ Strain $(\%)$} \\
\hline & & \multirow{3}{*}{$\begin{array}{l}\text { Axial } \\
\text { max. }\end{array}$} & \multicolumn{4}{|c|}{ Diametral } \\
\hline & & & \multicolumn{2}{|c|}{ Vent Cup } & \multicolumn{2}{|c|}{ Shield Cup } \\
\hline & & & $\underline{\text { Min. }}$ & Max. & Min. & Max \\
\hline & $\overline{\mathrm{FC} 0334}$ & 19.6 & -13.8 & 10.9 & -14.8 & 10.8 \\
\hline BCI-34 & FC0336 & 15.9 & -15.9 & 12.7 & -14.4 & 12.2 \\
\hline BCI-35 & FC0339 & 18.3 & -16.8 & 12.7 & -16.5 & 14.2 \\
\hline BCI-36 & FC0333 & $\mathrm{NM}^{*}$ & $\mathrm{NM}$ & $\mathrm{NM}$ & $\mathrm{NM}$ & NM \\
\hline
\end{tabular}

*Not Measured; capsule was broken up.

Subsequent comparison of the preimpact fuel pellet weight with the weight of the fuel recovered from the capsule indicated that a maximum of 0.187 grams of plutonia had been released. A particle size analysis was conducted on all of the fuel recovered from capsule FC0339; the results of this analysis are presented in Table II.

\section{d. BCI-36}

Capsule FC0333 was impacted against a 25.4-mm-thick structural steel plate at $75 \mathrm{~m} / \mathrm{s}$ and $1,090^{\circ} \mathrm{C}$ on 13 February, 1997. The capsule was pretreated for $200 \mathrm{~h}$ at $1,287^{\circ} \mathrm{C}$ (iridium alloy clad temperature) in vacuum before impact testing. There was no detectable deformation of the steel target.

Postimpact examination revealed that the capsule impact face was centered at approximately $350 \mathrm{deg}$ from the weld start. The clad was breached by several large cracks, including a weld failure. The entire fuel pellet was released into the containment can. The contact portion of the capsule impact face cold-welded to the lid of the tantalum containment can. Approximately $75 \%$ of the vent cup separated from the impact face and was recovered from the containment can in two pieces. The impact face portion of the vent cup remained attached to the remainder of the clad body. Because of the extensive clad breakup, it was not possible to obtain meaningful capsule strains.

Although the girth weld of capsule FC0333 failed over approximately $75 \%$ of the clad circumference, the weld remained intact on the flattened portion of the impact face. Macroscopic examination of the weld failure revealed numerous slivers of deformed metal projecting from the fracture surface. The underlying weld shield contained an intermittent crack in the equatorial location corresponding to the girth weld failure.

The largest of the dislodged vent cup pieces accounted for approximately one-half of the cup and included the entire vent assembly. Examination of the cup interior revealed a deep crease in the frit support metal and cracking along the circumference of the assembly and in the frit material. An axial crack that extended to the weld failure was located at approximately $200 \mathrm{deg}$ from the weld start and measured approximately $4.9 \mathrm{~mm}$ in length 
and approximately $1.8 \mathrm{~mm}$ at maximum width. This failure appeared to have been caused by differential fuel fragment displacement.

The other dislodged vent cup piece, which comprised approximately $25 \%$ of the vent cup, was roughly rectangular in shape with one side terminating at the weld failure. This piece measured approximately 13.7 by $25.0 \mathrm{~mm}$. A series of five hairline axial cracks were observed on the fracture surface of the weld failure. These cracks had an approximate length of $5.0 \mathrm{~mm}$.

Three transverse breaching cracks were observed on the cup radii of the impact face; two in the shield cup and one in the vent cup. Examination of the interior surface of the impact face revealed the breaching transverse cracks noted above and several nonbreaching axial cracks located at the edge of the impact face. The hairline vent cup crack had a length of approximately $9.2 \mathrm{~mm}$. One of the shield cup cracks measured approximately $10.5 \mathrm{~mm}$ in length; the other transverse shield cup crack had a length of approximately $15.2 \mathrm{~mm}$ and a maximum width of approximately $2.3 \mathrm{~mm}$.

Several breaching cracks were observed in the shield cup. One axial crack was located at approximately $200 \mathrm{deg}$ and appeared to match the axial crack on the largest dislodged vent cup piece. This crack also extended to the weld failure and measured approximately $10.4 \mathrm{~mm}$ in length and $1.4 \mathrm{~mm}$ at maximum width. Two relatively wide breaching cracks were observed on the flattened end of the shield cup. The largest of the two measured approximately $14.1 \mathrm{~mm}$ long and $7.1 \mathrm{~mm}$ at maximum width; the widest portion of the crack was located on the radius of the shield cup impact face. The other crack measured approximately $6.1 \mathrm{~mm}$ in length and had a maximum width of $1.4 \mathrm{~mm}$.

After postimpact examination, the capsule remains were photographed, and the fuel pellet fragments were carefully examined. No unusual discoloration or deposits were observed on the original surface of the fuel pellet nor on fracture surfaces that exposed the pellet interior. A Quick-Look report that documented the preliminary findings of the postmortem examination was issued on 13 February. A particle size analysis was conducted on all of the fuel recovered from the tantalum impact can; the results of this analysis are presented in Table $\Pi$.

\section{Research and Development}

\section{High-Silicon Fuel Characterization (HSC) Study}

The purpose of the high-silicon fuel study was to determine the effect of fuel impurities on the response of the GPHS to conditions that were baselined during the Galileo/Ulysses test program. Four fuel pellets fabricated and encapsulated at LANL in 1993 and 1994 were selected for use in the first two half-module impact tests in this test series.

The two pellets selected for the first test, HSC-1, were fabricated from low-enrichment $\left(<82 \%{ }^{238} \mathrm{Pu}\right)$ fuel and contained relatively high concentrations of silicon $(905$ and $1,059 \mathrm{ppm})$. The GPHS capsules containing these pellets were loaded into a graphite 
impact shell (GIS), which was designated GIS A. This GIS was then paired with another GIS (designated GIS B) and was loaded into a GPHS module.

The two pellets selected for the second HSC test had calculated silicon contents of 415 and $605 \mathrm{ppm}$. The GPHS capsules containing these pellets were loaded into a GIS (designated GIS D), paired with another GIS (designated GIS C), and then loaded into a GPHS module for heat treatment.

Both GPHS modules were treated in a module reduction and monitoring facility (MRMF) vacuum system. During the MRMF treatment, each module was placed in a vacuum chamber that was evacuated and then backfilled with argon. Each module was maintained at a constant temperature during the MRMF treatment. The module containing GIS A stabilized at $920^{\circ} \mathrm{C}$. The module containing GIS D stabilized at $862^{\circ} \mathrm{C}$. In each case, the MRMF treatment continued until a fuel stoichiometry of approximately $1.98 \mathrm{O} / \mathrm{Pu}$ was achieved.

After MRMF treatment, each module was soaked at $1,074^{\circ} \mathrm{C}$ (module surface temperature) in a vacuum for an extended time period; this treatment temperature was calculated to give a fuel temperature of $1,461^{\circ} \mathrm{C}$. After the aging treatment, the modules were removed from the aging furnaces, and GIS A and GIS D were loaded into GPHS half-modules for impact testing. Both impact tests (HSC-1 and HSC-2) were performed in mid-1995; the results of these tests have been presented in previous monthly reports and were documented in LANL report LA-13101-MS "General-Purpose Heat Source: Research and Development Program: High Silicon Fuel Characterization Study; Half Module Impact Tests 1 and 2."

The remaining two GISs (GIS B and GIS C) were reinserted in the aging furnace, and heat treatment continued at $1,074^{\circ} \mathrm{C}$. GIS B was removed from the aging furnace during the first week of November, 1995, after a total of 235 days at temperature. The GIS was then temporarily placed in a helium-atmosphere glovebox. GIS C was removed from the aging furnace on 8 January, 1996, after a total of 262 days at temperature. After removal from the aging furnace, GIS $\mathrm{C}$ was also moved into the helium-atmosphere glovebox with GIS B. On 31 May 1996, both GISs were moved to a vacuum furnace for long-term storage. The fuel capsules in GIS B had silicon contents of 1,127 and $776 \mathrm{ppm}$; the GIS C capsules had silicon contents of 336 and $325 \mathrm{ppm}$.

\section{Aqueous Recovery Operations}

Dissolution and precipitation operations were suspended at the beginning of October 1996 to accommodate the November shutdown/cleanout inventory. Aqueous recovery operations resumed on 25 March 1997, with the dissolution of another small (approximately $25 \mathrm{~g}$ ) batch of ${ }^{238} \mathrm{PuO}_{2}$ scrap. 


\section{Investigation Of Urania/Plutonia Simulants}

In this quarter, we continued to investigate potential substitutes for the ${ }^{238} \mathrm{UO}_{2}$ that has historically been used for uncontained heat source safety tests. On 5 February, two pellets composed of $\mathrm{HfO}_{2}$ were encapsulated in flight-quality GPHS clad/vent-sets. The capsules (designated as SC0144, and SC0145) were helium leak checked and then submitted for ultrasonic testing of the girth welds. Both capsules met the helium leak and ultrasonic test requirements for flight-quality GPHS capsules.

\section{Accelerated Oxygen Exchange}

We continued to investigate methods of accelerating the ${ }^{16} \mathrm{O}$ oxygen exchange process. Previously, a thick-walled tantalum container was loaded with approximately $150 \mathrm{~g}$ of unexchanged ${ }^{238} \mathrm{PuO}_{2}$ and a small amount of ${ }^{16} \mathrm{O}$-enriched water and was then welded shut. In October 1996, the tantalum vessel was decontaminated, leak-checked, and then loaded into a stainless-steel secondary containment vessel. The assembly was then submitted for neutron emission rate (NER) measurement. The NER measurements indicated that in the 22.5 months that elapsed from the time of container loading, the fuel NER had dropped from 13,000 neutrons $/ \mathrm{s} \cdot \mathrm{g}{ }^{238} \mathrm{Pu}$ to $8,000 \mathrm{n} / \mathrm{s} \cdot \mathrm{g}$. This result suggests that long-term storage of fuel in contact with ${ }^{16} \mathrm{O}$ water might preclude the need for oxygen exchange treatment during fuel processing.

On 22 January 1997, the tantalum container was cut open, and the ${ }^{16} \mathrm{O}$ water was allowed to evaporate from the fuel in an inert-atmosphere glovebox. The NER of the powder was measured for a third time on 4 February. Surprisingly, this measurement indicated that the NER had increased to 12,000 neutrons $/ \mathrm{s} \cdot \mathrm{g}{ }^{238} \mathrm{Pu}$. This result is confusing because the second NER measurement was taken when the fuel was in contact with water that undoubtedly contained some amount of ${ }^{17} \mathrm{O}$ and ${ }^{18} \mathrm{O}$ and because little or no additional exchange would be expected to occur as the water evaporated. Consequently, the third NER measurement would be expected to be the lowest of the three.

\section{Helium Release Studies}

In this quarter, we continued to make progress in procurement and installation of a glovebox system to perform helium release studies on ${ }^{238} \mathrm{PuO}_{2}$. In early February, a number of hydraulic system parts, including a pump, were received at LANL. The arrival of these components facilitated installation work on cooling water plumbing for the radiofrequency (RF) coils and cables. All installation work on the hydraulic system was completed by the end of March.

\section{E. Project Management}

Primavera updates were received from Orbital Sciences Corporation (OSC) at the beginning of each month. Three monthly status reports for the Cassini program were submitted to OSC on schedule. 


\section{LIGHT-WEIGHT RADIOISOTOPE HEATER UNIT (LWRHU) PROGRAM}

\section{A. Cassini Heat Source Production}

A total of 180 LWRHU capsules were previously loaded into aeroshells, welded into product cans, and transferred to the PF-4 vault for storage. By the end of March, a final schedule for shipment of the product cans to Kennedy Space Center (KSC) had been established.

At the beginning of the quarter, we worked to arrange the LWRHU shipment in three 9968 containers provided by EG\&G MAT. Although any returns from KSC were required to be shipped in 9968 containers, we also worked on preparing a justification to ship LWRHUs in $6 \mathrm{M}$ containers. By mid-February, the LANL shipping group had agreed that leaktestable DOT-6M containers would meet DOE orders and Department of Transportation (DOT) requirements and could be used as a backup to the 9968 containers.

On 25 February, we received a certificate of inspection (COI) from the DOE Albuquerque Operations office (DOE-ALO) that accepted 128 LWRHUs for shipment to KSC. A shipping plan was prepared on the basis of 128 LWRHUs packaged in eight 9968 containers and was forwarded to the LANL shipping group.

On 11 March, we were directed by representatives from NASA's Jet Propulsion Laboratory (JPL) to modify the KSC shipment to 129 capsules. By the end of March all 129 LWRHUs had been loaded into 9968 containers and were awaiting shipment.

\section{B. LWRHU Production Qualification}

On 28 June 1996, LWRHU heat source LRF-294 was impacted against a steel target plate at $53.5 \mathrm{~m} / \mathrm{s}$. The test was conducted at ambient temperature in the 7-in. launcher. Preliminary results of the postmortem examination were documented in previous reports.

In October 1996, the impacted LWRHU aeroshell was disassembled. There was no discernible evidence of impact on the surface of the LWRHU capsule. In this quarter, we continued with metallographic analysis of a capsule cross section and particle size analysis of the fuel pellet.

\section{LWRHU Safety Testing: Sequential Impact Tests}

In July and August 1997, a series of sequential impact tests were performed on simulantfueled LWRHUs to determine energy thresholds for the destruction of various LWRHU components. These tests were performed to provide data for the Cassini final safety analysis report (FSAR) and were documented in previous monthly reports. In this quarter, we continued to work on preparation of a topical report that would formally document the results of these tests. 


\section{60-WATT HEAT SOURCE}

Heat source 16-040 (containing capsule FC0029) was placed in an aging furnace under vacuum at $650^{\circ} \mathrm{C}$ on 14 December 1995 and reached thermal equilibrium on 15 December. The heat source was removed from the aging furnace on 9 July 1996 and was submitted for radiographic examination. On 26 July 1996, the heat source was returned to the furnace for an additional six months of heat treatment at $650^{\circ} \mathrm{C}$. The heat source was removed from the furnace on 4 March 1997. Radiological surveys of the furnace did not reveal the presence of any contamination.

\section{1-kW SHIPPING CONTAINER}

The LANL inventory of 1-kW hardware as of 31 March 1997 is shown in Table V.

Table V. LANL Inventory of 1-kW Hardware as of 31 March 1997

Type of Hardware Number of Items

Primary containers $\quad 4$

Primary lids $\quad 2$

Secondary containers $\quad 2$

Secondary lids $\quad 2$

Product cans $\quad 28$

\section{PROGRAMMATIC MEETINGS AND VISITORS}

On 25 and 26 February, a WSRC employee assisted LANL staff in upgrading the ICEPAK ultrasonic test (UT) data analysis system.

On 25 March, four Russians from the Chelyabinsk facility toured the ${ }^{238} \mathrm{PuO}_{2}$ operations in the Plutonium Facility (Building PF-4). 